\title{
CONFLICT AND SOLIDARY DETERMINING PARAMETERS OF THE NEGATIVE AND POSITIVE PROCESSES OF THE LEGAL ASPECT OF THE SOCIAL LIFE (THE PROBLEM OF ESTABLISHING REGULAR ASSOCIATIONS)
}

\begin{abstract}
The present paper addresses the problem of establishing the conflict and solidary social determinants of the negative and positive processes of the legal aspect of life. The study reveals that the legal aspect of social life has a socially interactive content, is built on social and legal interactions that fall into two main types - cooperation and conflict. It is stated in the article that the dynamics of the legal aspect of social life in its positive and negative manifestations is determined by the solidarity and conflict types of social ties, respectively. Law, focusing on the conflict and solidarity manifestations of the legal aspect of life, uses negative and positive instruments in order to minimize conflicts and expand the scope of cooperation in social and legal life.
\end{abstract}

Keywords: law, legal aspect of social life, law generation, society, social interaction, communication, communicative theory of society, sociology of law, conflict, cooperation, negative legal instruments, positive legal instruments.

\section{Introduction}

In the present article, the author attempts to detect and establish a relationship between the negative/positive sides of the legal aspect of social life and the matter of law, which is represented by diverse legal tools that perform tasks and functions that correspond to the objects of application. External forms of manifestation of negative and positive social and legal life are quite well known: on the one hand, these are crimes (offences against the law, violations of legislative prohibitions) and other offences that encroach on the foundations of society and the state, affecting the rights and legitimate interests of citizens. It is the shadowy

${ }^{1}$ Derzhavin Tambov State University 
legal life, which, as a rule, has a nearcriminal or criminal nature. These are various defective manifestations in law, which lead to defects in its social action, etc. On the other hand, it is the lawabiding and lawful behavior of citizens (individuals) who exercise their social and legal activity in the parameters of what is permitted and possible from the point of view of law; these are various contracts and agreements between legal entities (individuals, corporations and other organizations, state entities and states), etc. However, in addition to these fairly visible external manifestations of social and legal life, there is also an internal (deeper) aspect. It is expressed in the fact that the negative side of the legal aspect of social lifeis, first and foremost, a conflicting social environment, the sphere of social and psychological tension and mutual opposition of social and legal entities, while the positive aspect of social and legal life is -a sphere of cooperation and mutual consent of parties -who are participants in legal and social interactions, the "pacified environment" of law. These deeper aspects of social and legal life (the ongoing process of social and legal interaction / communication) are the direct object of state legal influence, which can be effective only if the mechanisms (instruments) of such influence are fully adequate to the nature of social situations of legal conflict and cooperation, where the former must be prevented, eliminated, or minimized, and the latter-supported and stimulated.

A number of research lines are used in the study that express scientific traditions formed in foreign and Russian legal science (academic schools of law). Firstly, we are talking about the established scientific experience of explaining the legal nature through the prism of communication phenomenon (interaction) as the ultimate layer of "social" in general and "social and legal" in particular (J. Habermas, E. Husserl, P. Berger, T. Luckmann, N. Luhmann, A. Schütz, T. Parsons, P. Bourdieu, M. van Hoecke, L.I. Petrazhitsky, P.A. Sorokin, G.D. Gurvich, N.N. Alekseev, M.M. Kovalevsky, A.V. Polyakov, I.L. Chestnov, L.S. Mamut, M.V. Antonov, V.V. Trofimov, et al.). Secondly, the scientific context related to the development and introduction of such a notion as "the legal aspect of social life" into the conceptual categorical apparatus of jurisprudence should be paid special attention to. This is a dynamic integrated 
category that allows the study of a variety of legal phenomena directly from the life, i. e. the level where the law really exerts its effect or is ineffective, accompanying or conditioning positive or negative social and legal consequences. The concept of legal life has been developing rapidly in recent years, which is reflected in the academic works of the author of the concept A.V. Mal'ko and supporters of this sociallyfocused point of view on the statics and dynamics of law (A.E. Mikhailov, V.A. Shiyanov, Yu.Yu. Vetyutnev, V.V. Trofimov, et al.). Thirdly, the conflictual and solidary content of social communication in its impact on the law is revealed on the basis of the two main paradigms of social reality that have developed in social science: in one case, researchers bring the conflict to the fore as the immanent aspect of the "social" side (G. Simmel, R. Dahrendorf, L. Coser, M. Deutsch and others); in another case, society is considered precisely from the standpoint of the individuals' inherent desire to live with each other in peace and cooperation: social structure, social life in general and its development are based only on agreement and solidarity (A. Comte, T. Parsons, E. Durkheim, et al.). The author of this study tries most objectively and purposefully in terms of jurisprudence (in the context of legal science) to link these two basic forms of social life (conflict and solidarity) with the law and the world of legal phenomena, as well as to derive stable connections from this in his study, where he directly tests the experience of applying for the named purposes the category of the "legal aspect of social life", more about which will be said in the outline of general discussions on the problem in the subsequent text of this article.

Within the framework of the present article, it is necessary to consider and solve certain related issues (tasks): 1) substantiate the usefulness of introducing into the academic discourse the concept of "legal life" as allowing the most deep and comprehensive study of the world of legal phenomena;2) to draw the attention of the reader to the deepest social sources of law, showing a crosssection of legal life at the level of interpersonal interaction (interaction);3) single out in the phenomenon of social interaction the conflicting and solidary sides filling the negative and positive aspects of legal life, and substantiate the influence of these phenomena on the 
matter of law, represented by various legal instruments.

\section{Materials and methods}

The study combines special legal concepts and categories with the categorical apparatus of philosophy and sociology, general and social psychology, since it is this synthetic basis that makes it possible to more accurately reveal the original meaning of a general social and legal phenomenon, in particular, the social nature of law and legal life, the socio-psychological atmosphere of legal communications, the socio-legal functions of the means of legal regulation of social processes in legal life. So, at the philosophical level of methodology, in order to understand the dynamic (as well as static) phenomena of the legal aspect of social life, the author uses the potential of dialectics as a doctrine of universal connection and development, its laws in the form of unity and struggle of opposites, the transition of quantitative changes to qualitative ones, negation of negation, its dual categories (form and content, phenomena and essence, etc.). In addition, based on this higher level of knowledge, methodological provisions regarding a worldview which is new to science, developed by synergetics (the doctrine of the self-organization of the elements of being, which studies structures of very different nature, explores how the interaction of various subsystems leads to the emergence of new states (parameters)), will be essential. This will become an important cognitive resource for understanding the nature of the legal aspect of social life in its negative and positive manifestations. It seems equally productive to use the modern socio-philosophical approach in characterizing the social basis of the formation and operation of law. Modern international and Russian social philosophy provides legal science with a new methodological basis for studying the social basis of law, the social conditionality of the dynamic processes of legal life, forming an updated view of society. This approach proposes to study social reality as a subjectively structured social object, as a social context, which is the ultimate reality, having not only a horizontal or latitudinal order, but also a vertical, fundamentally essential one, where people's interaction, or activity communication, lies at the basis and makes the fundamental principle, the matrix of all sociality, everything social. It can be noted here that among the legal 
paradigms (the role of which is largely played by the type of legal understanding), the communicative approach (type of legal understanding) in jurisprudence (as well as discursivedialogical jurisprudence, sociallyinteractive concept of law, deliberative and "life-legal" approaches and some others) will be of particular importance. Its important heuristic role is that this approach offers to understand law as an instrument of human interaction, and not as a self-sufficient phenomenon (M. van Hoecke). In the development of this direction, the principle of systematic study of social phenomena and processes as a structurally differentiated integrity, in which each element of the structure has a specific functional purpose (structural-functional analysis), will be used as an adequate cognitive device at the general scientific level for the subject of research. This method allows one to define the role of one of the elements of the system in relation to another one, and also to show the dependence of the elements on each other (changes in one part of the system are derived from changes in the other part, and the overall "structural result" is due to the contribution of each of the "elements"). From the standpoint of structural and functional analysis, the interaction systems “individual-ndividual”, "individual-society" are made up by interdependent functional relationship between the acting (participating in the interaction) entities ("arguments"), the functions of which in the process of interaction become common agreed standards of "legal communication" (L.S. Mamut). Such an understanding will allow us to establish why the negative side of the legal aspect of social life (which from the substantive social side manifests itself in conflict interactions in social systems) determines the application of the characteristic (negative) legal instruments in order to minimize the conflict (negative) manifestations in the law, and the social and legal positive aspect determines the application of different in nature and focus instruments of legal influence (mainly - positive legal instruments). Since the main issue is the study of the social foundations of law, this will naturally express the use of such an interdisciplinary methodological resource as the state-of-the-art sociological approach to the study of law, which, in order to encompass legal reality, is based not on the formal legal provisions, but directly on the social 
conditions of life itself (social and legal life).

\section{Results and discussion}

3.1. On the usefulness of introducing the concept of the "legal aspect of social life" into academic discourse

The legal aspect of social life, as well as the economic, political, cultural and other spheres of life, develops according to certain objective laws. The emergence, dynamics, completion of legal life, its positive and negative aspects - all this is a manifestation of certain constantly acting determining factors that determine what the legal life of society will be, in which direction to move and develop in time and space. At

2 See: Mal'ko, A.V. The category of "legal life": problems of formation // State and Law. 2001. No. 5. P.p. 5-13; Trofimov, V.V. Legal life: theoretical and socio-philosophical problems of research // Legal policy and legal life. 2003. No. 4. P.p. 124-133; Legal life in modern Russia: theoretical and methodological aspect / Ed. by N.I. Matuzov \& A.V. Mal'ko. Saratov, 2005; Zatonsky, V.A., Mal'ko, A.V. The category of "legal life": the experience of theoretical understanding // Jurisprudence. 2006. No. 4. P.p. 4-17; Mal'ko, A.V., Mikhailov, A.E. The legal aspect of social life. Saratov, 2007; Shiyanov, V.A. The legal system and the legal aspect of social life: theoretical the same time, it is obvious that it is not enough for people to remain only observers of the processes of the legal life of society, following its course. It is important for a person to learn how to skillfully manage these processes (law generation, lawmaking, law enforcement, including law usage, performance of rights, clearance of rightslaw application, law interpretation, law teaching, law education,reform,termination, law compensation, correction (mistakes, defects, collisions), etc.). However, in order to achieve this, it is necessary to understand the initial objective laws (partly with the introduction of the subjective element) of the legal aspect of social life, the categorical matrix ${ }^{2}$ of

aspect of interaction: Author's abstract of dissertation for the degree of Cand. Sc. (Law). Moscow, 2008; Trofimov, V.V. The concept of legal life: theoretical and methodological significance // Legal policy and legal life. 2009. No. 2. P.p. 61-68; Mal'ko, A.V., Trofimov, V.V. Theoretical and methodological significance of the concept of "legal life" // State and Law. 2010, No. 7. P.p. 5-13; Nozdrin, A.N. Legal life as a category of modern legal science: Author's abstract of dissertation for the degree of Cand. Sc. (Law). Mariupol, 2013; Mal'ko, A.V., Trofimov, V.V. Legal Life: Conceptual, Categorical and Methodological Analysis Experience // Journal of the 
which is formed in legal science precisely in order to be able not only to hypothetically suggest the objective (objective-subjective) laws of the life of law but to research them with the maximum results, and to provide the results of the research for the application in political and legal practice.

In addition, the author points out that the new categorical matrix, which is the concept of the "legal aspect of social life", does not at all obscure the subject of legal knowledge (since critics of this

Siberian Federal University. Series: Humanities. 2015. Vol. 8. No. 8 . P. 1652-1660; Mal'ko, A.V., Ponomarenkov, V.A. Legal life of modern society: social factor analysis. Moscow, 2015; The legal life of society: problems of theory and practice / Ed. by A.V. Mal'ko. Moscow, 2016; Legal life of modern Russian society: levels, sections, segments / Ed. by A.V. Mal'ko. Moscow, 2016; Mal'ko, A.V., Trofimov, V.V. The legal life of society as an object of the theory of law (to the formulation of the problem) // State and Law. 2017. No. 5. P.p. 39-50; The legal life of Russian society in the context of globalization / Ed. by A.V. Mal'ko. Moscow, 2017; Mal'ko, A.V., Trofimov, V.V. The legal life of society as an object of legal policy in the context of globalization and regionalization: monograph. Moscow, 2018, et al.

3 See, for example: Baranov, V.M. Shadowy law. Nizhny Novgorod, 2002; Matuzov, N.I. Legal life as an object of scientific research // Legal life in modern theoretical construction emphasize this, saying that the concept of the "legal aspect of social life" is just "fictitious", "a literary image", which is not characteristic of scientific legal knowledge, introducing supposedly unnecessary elements into $i^{3}$ ), but, on the contrary, gives it not only "technical"positivistic (legal-dogmatic), but truly social (social and legal) character, thus making it close to the ideal image of legal science. The socalled "pure" jurisprudence does not

Russia: theoretical and methodological aspect / Ed. by N.I. Matuzov \& A.V. Mal'ko. Saratov, 2005. P.p. 9-38; Bryzgalov, A.I. Jurisprudence today: theoretical and methodological problems that await solutions // Journal of Russian Law. 2001. No. 6. P. 48; Idem. On some theoretical and methodological problems of legal science at the present stage // State and Law. 2004. No 4. P.p. 20-21; Aslanyan, N.P. The concept of civil law reality: formulation of the problem // Society, politics, economics, law. 2010. No. 1. C. 69-76; Eadem. The concept of legal reality: statement of a civilistic problem // Bulletin of the Irkutsk State Economic Academy. 2012. No. 5. P.p. 100-108; Lichman, B.V. The multiconceptual methodology of Russian jurisprudence // Bulletin of the Ural Institute of Economics, Management and Law. 2013. No. 2. P.p. 60-67; Chernykh, E.N. The category of "legal life": issues of methodology // Legal policy and legal life. 2014. No. 3. P.p. 8-15, et al. 
even try to see these obvious truths, but is forced to admit them in one way or another when "life" itself forces it to do it (showing at one point another gap between "law in books" and "law in life" or focusing the attention on one or another "mass" negative manifestation of legal life - legal nihilism, total corruption, inefficiency of legal regulators, etc.), making it pay attention to the complex social and legal processes of the life of law.

It is precisely this complexity of the world of legal phenomena, their diversity and inconsistency, that the research strategy of "legal life" is focused on. As K.V. Shundikov quite correctly notes: "The concept of legal aspect of social life challenges the problem of the complexity of the object of legal science; in fact, it is an attempt to develop a more adequate (compared to previously used) methodological algorithm for solving it. Accordingly, the problem of searching for scientific tasks

${ }^{4}$ Shundikov, K.V. Synergetic approach in jurisprudence. Problems of methodology and experience of theoretical application: monograph. Moscow, 2013. P. 111.

5 Law and culture / Ed. by N.S. Sokolova. Moscow, 2002. P. 66; On the philosophical and methodological of methodological programs of the level of complexity corresponding to the object also becomes more relevant" "This approach expresses the natural desire of science to gradually expand the boundaries of cognition of legal reality, as well as the awareness of the need to include in the research field of jurisprudence the general cultural factors characterizing the level of social development. This is what the concept of the legal aspect of social life implies ${ }^{5}$.

\subsection{The problem of identifying} the social origins of the legal aspect of life. As was mentioned above, in order to be able not only to observe the processes of the legal aspect of social life, but also to skillfully control them and, if necessary, to correct them and carry out other actions to streamline the elements of the legal aspect of life, one must, of course, know its laws. Therefore, the task is simple: to understand and describe the deepest aspects of the legal aspect of social life, to establish its main

significance of the concept of the legal aspect of social life, see also: Nevvazhay, I.D. History and philosophy of science. In 2 parts. Part 2: Philosophical problems of social and humanitarian (legal) sciences. Saratov, 2012. P.p. 71-81, et al. 
determinants, for which it is important to realize that legal life is part of social life, which requires the same in-depth understanding of the nature of society and the laws of its evolution. This will make it possible to answer many questions about what is the legal aspect of social life. It must always be remembered that it is in the course of social life that the activity of people is transformed into the corresponding legal forms and linguistic meanings, therefore, in order to understand the law in all its life manifestations, it is necessary to start with the study of social life. A common sociological platform should be present at the core of the process of researching the legal aspect of social life. With the help of a socially-focused approach, it will be possible to study law from the standpoint of its fundamental principles or root causes, i. e. to reach the objective grounds for the formation and functioning of law, the initial and the derivative, the positive and negative phenomena of the legal aspect of social life. In legal life, those sides and phenomena that are reproduced in the context of social being as such cannot

${ }^{6}$ For more detailed information, see: Trofimov, V.V. The socially interactive nature of the legal aspect of life as a but find their reflection. Therefore, a deeper investigation of the matter of social life makes it possible to discover many properties of the legal aspect of life, to understand the laws of its evolution, and its dynamic development ${ }^{6}$.

Thus, of particular interest may be the study of the reasons why in some cases the legal aspect of social life develops according to positive scenarios (for example, participants in a full partnership carry out joint activities, fulfill their obligations, etc.), and in others, legal contradictions between shareholders (founders) can lead to the collapse of the entire enterprise. In the first case, law is intended only to help further progress in social and legal relations (by offering certain additional legal opportunities - subjective rights and solidary legal forms (primarily, forms of contracts, etc.)), while in the second case, the functions of legal instruments will be reduced to law enforcement and these or those restrictions, as well as to the establishment of borders between the conflicting parties. It is possible to

dynamic process // Legal policy and the legal aspect of life. 2016. No. 3. P.p. 1321. 
reveal such negative and positive sides of the legal aspect of social life through the analysis of their inherent sociallyinteractive content (and this content consists of the conflict and solidarity types of social relationships, as in one case, people who participate in legal life come to agreements and make mutual concessions, while in other cases they argue and try to defeat the opposing side, having in mind exclusively their own interests, even if their satisfaction can harm others). It is this social context of legal life that has an objective character with respect to law, determines the emergence, development, and functioning of the legal form of social relations, and it is precisely this that must be subjected to profound analysis ${ }^{7}$.

It is important to establish at the beginning of such studies that the analysis of the phenomenon of social

${ }^{7}$ Joachim J. Savelsberg, Terence Halliday, Sida Liu, Calvin Morrill, Carroll Seron, Susan Silbey. Discussion Law \& Society Review at Fifty: A Debate on the Future of Publishing by the Law \& Society Association 50 (4): 1017-1036 DEC 2016 (Law and Society Review). URL: https://doi.org/10.1111/lasr.12246;

Maksymilian Del Mar. Law, Culture and Society: Legal Ideas in the Mirror of Social Theory. By Roger Cotterrell 41 (4): 983-985 DEC 2007 (Law and Society determinism of the legal aspect of life should begin with the ultimate level of the "social"- with consideration of interaction (from lat., interactio - I interact) - the activity communication of individuals as a matrix of social processes. In this case, it will become possible to understand the legal dynamics associated with the peculiarities of specific social situations in which a human life and, therefore, the legal aspect of social life takes place. Communication is the basis of the legal aspect of social life ${ }^{8}$.

Different in their functional nature sides of the interaction (interaction, communication) of social and legal entities, embodied in a wide variety of forms and making the hypostasis of the legal aspect of life (a dynamic category that reflects the life of society associated with law, initial and derivative, positive and negative, static

Review).

URL: https://doi.org/10.1111/j.15405893.2007.00331_1.x; Sandra R. Levitsky, Rachel Kahn Best, Jessica Garrick. «Legality with a Vengeance»: Reclaiming Distribution for Sociolegal Studies 52 (3): 709-739 SEP 2018 (Law and Society Review). URL: https://doi.org/10.1111/lasr.12349.

8 See, for example: Polyakov, A.V. Communicative legal understanding: Selected works. St. Petersburg, 2014. 
and dynamic legal phenomena), determine the content of law, its nature, the general vector by which the law, and with it the legal aspect of social life, develop.

Social interaction should be regarded only as a general factor in the evolution of the legal aspect of social life, since it is on it that the effect of all other social factors (economic, political, demographic, cultural, etc.) is focused and by which it is determined. Economics, politics, culture and many other subject areas of reality surrounding us - all these are derivative phenomena from the basic phenomenon of interaction proceeding from the nature of human existence that includes all other aspects of social life, including its legal aspect ${ }^{9}$.

The processes of the legal aspect of life represent the variety of proto-, meta- and post-legal interactions. The legal sphere of social life is the element of interactions between people connected with the law (transactions, damages in tort, copyright relations, mechanisms of responsibility, etc.). This is so, since social life, the form of which

9 See also: Trofimov, V.V. Sociallyinteractive (communicative) environment and its cultural-universal is its legal aspect, is the sphere of dominance of "interaction" phenomenon, which makes society and the entire social world single and whole, moreover, whole not as a mechanical aggregate of parts, but as a social and legal reality that unites, integrates, and binds these parts, provides their reproduction and transformation.

"The whole vast ocean of the world history of mankind", wrote P.A. Sorokin, "is made up of individual streams and rivers, which are individual long and instant interaction processes. Some of them, namely, the organized flows of interaction, have certain coastal shapes, a certain channel, while others are unorganized processes or groups, which are similar to shapeless swamp water that does not have a specific channel, clear coastal outlines and a pronounced course... As the sea is made up of separate streams, rivers and flows, so the ocean of humanity's social life is

role in the processes of legal dynamics // Legal Technology. 2016. No. 10. P.p. 316-321. 
made up of such processes of interaction" $"$.

All social (including legal) life begins with elementary interaction between individuals (and then, ascending, reaches the form collectivesocial entities), which in their mutual relations create prototypes of all interactions of this kind, and therefore the first examples of mutual measures of freedom and common life standards that are necessary as management tools to maintain the effective functioning of these social interactions.

As P. Berger and T. Luckmann note, the social order is a human product or, more precisely, continuous human production. It is created by man in the process of constant externalization. The social order in its empirical manifestations is not biologically given or derived from any biological data. There is no need to add that the social order is also not a given of the human natural environment, although its individual features may be factors that determine certain characteristics of the social order (for example, economic

10 Sorokin, P.A. Public textbook of sociology. Articles of different years. Moscow, 1994. P. 27. measures, technological devices). The social order is not part of the "nature of things" and does not arise according to the "laws of nature". It exists only as a product of human activity ${ }^{11}$.

The social essence of law and the laws of evolution of the legal aspect of social life are largely determined by the logic of social and legal interaction. By virtue of their social teleology (goalsetting), certain behaviors of individuals (social subjects) are legitimized, gain binding power and become normative attributes for the surrounding reality. At the same time, the type of social interaction depends on what kind of regulators will be at the "output", and what kind of law will become applicable for the relevant relations.

\subsection{Conflict and cooperation as} an objective reality of law. Answering the question about the type of social interaction, it should be noted that depending on the prevailing "energies", all possible types of interactions objectively fall (can be differentiated) into two opposite types: competition and cooperation (conflict and cooperation).

${ }^{11}$ See: Berger, P. \& Luckmann, T. Social structuring of reality. A treatise on the sociology of knowledge. Moscow, 1995. P. 89. 
This dichotomous correlation (from the point of view of the dialectical approach - opposing and simultaneously uniting opposites) essentially defines the state and dynamics of the social world and its life (its positive and negative aspects), which develops at the junction of solidary and conflict social programs, and, accordingly, that segment of social life that is associated with legal forms or, in other words, the legal aspect of life.

Ontologically, cooperation and conflict appear as two dialectically opposing and complementing each other in individual consciousness and social practice, moral and political and legal paradigms, regulators and drivers of people's activities, their behavior and actions. At the same time, it should be recognized that both of these paradigms found their place in explaining what lies at the basis of social development, what moves people, makes them look for and find new ways and methods of living together in the interests of ensuring an increasingly comfortable way of life. However, regarding which of the phenomena (solidarity or conflict) has a

12 Grevtsov, Yu.I. Sociology of law. St. Petersburg, 2001. P. 193. leading role in determining social life, the opinions of scientists differ.

Yu.I. Grevtsov classifies opinions on the problem of the dominance of solidarity and conflict models of interaction in public life into two main groups: "Some scientists (A. Comte, T. Parsons) believed that the social structure and social life in general and its development in particular are based only on agreement and solidarity. Moreover, solidarity, in their opinion, is solely the result of interaction and cooperation... On the other hand, G. Simmel, R. Dahrendorf and others emphasized, in particular, that social life is generated and developed through opposition, hostility, alertness, which lead to social tension in that or another section of social life" ${ }^{\prime 2}$.

The desire for cooperation, compromise, partnership, and at the same time susceptibility to conflict, disagreement, and confrontation - these are two main social alternatives, in accordance with which the development of the entire public legal system and the legal aspect of social life takes place, in the parameters of which certain legal 
forms exist that are aimed at both the suppression of conflicts, localization of the zone of their course in public practices, and enhancing cooperation, expansion of areas of solidarity in public life.

Social and legal processes are formed and implemented precisely because of these two basic action strategies of socially interactive systems. In conflict or cooperation, social subjects create a "minus" or a "plus" (a negative or a positiveaspect) of social relations, affect the legal image of the social world, adding (introducing) to it either the elements of measures of state legal influence preventing or resolving conflicts (if they dominate in practice) or enriching the legal aspect of social life with new co-operation agreements (conventional legal forms) if social actors show solidarity, consent and mutual respect.

As was noted above, external forms of manifestation of the negative and positive aspects of social and legal life are quite well known: on the one hand, these are different types of crimes (offences against the law, violations of legislative prohibitions) and other offences that encroach on the foundations of society and the state affecting the rights and legitimate interests of citizens. It is the shadowy legal life that flourishes in modern conditions and, as a rule, has a near-criminal or criminal nature. These are the numerous defective manifestations in law which lead to defects in its social action (i. e., lead to social and legal conflicts and clashes), etc. On the other hand, it is the lawabiding and lawful behavior of citizens (individuals) who exercise their social and legal activity in the parameters of what is permitted and possible from the point of view of law; these are various contracts and agreements between legal entities (individuals, corporations and other organizations, state entities and states); it is the organization of joint ventures (commercial and non-profit organizations) for the achievement of common goals, etc.

However, it should be understood that in addition to these fairly visible external manifestations of social and legal life, there is always the internal (deeper) aspect as well. It is expressed in the fact that the negative side of the legal aspect of social life is, first and foremost, a conflicting social environment, the sphere of social and psychological tension and mutual opposition of social and legal entities, while the positive aspect of social 
and legal life is a sphere of cooperation and mutual consent of parties who are participants in legal and social interactions, the "pacified environment" (M.M. Kovalevsky) of law. These deeper aspects of social and legal life (the ongoing process of social and legal interaction / communication) are the direct object of state legal influence, being the object of legal influence which can be effective only if the mechanisms (instruments) of such state legal influence (control) are fully adequate to the nature of social situations of legal conflict and cooperation, where the former must be prevented, eliminated, or minimized, and the latter supported and stimulated.

Social and legal development (of a progressive nature) is, by its initial nature, a process of solidarity and integration of joint efforts in order to achieve certain goals (in general civil life, entrepreneurship, the political plane, the field of national security, etc.). Legal progress implies the adoption and implementation of legal decisions in the format of cooperation, dialogue, exchange of views, based on the coordination of positions. This positive side of social-legal interaction could undoubtedly be the main line for the long term development of society, allowing social actors to fully experience the potential of law, its role in the formation and socialization of the individual, etc. For example, in case of such a universal legal institution as the institution of human rights and freedoms, positive social interaction is, undoubtedly, the key to its effective implementation in practice. The same can be said about the legal form of contract, which was brought to life precisely by the desire of individuals to communicate and jointly resolve many issues, benefiting from such cooperation.

This positive hypostasis in the life of law is opposed by another side of the legal aspect of social life, i. e. conflict, competition (sometimes quite aggressive). And this negative type of social interaction also significantly affects the legal development of society. The existing conflict relations between social actors are negative in themselves, as they damage (sometimes destroy) certain elements of the social system, but at the same time they do not exclude a result-focused aspect. Conflicts lead to the emergence of legal institutions and regulators whose function is to prevent possible conflicts or resolve them, including via sanctions, negative obligations and prohibitions of the 
implementation of a particular socialpolitical, social-economic and other activities. Despite the negative nature of the conflict processes, they also constitute the content of legal life and determine in many respects its dialectics and patterns of development (evolution). A different situation would be impossible, by definition, since there always occurs a clash of interests of different social actors.

It is in the culture of social interaction that the prerequisites for the dynamic development of law, the legal aspect of social life, the origins of legal forms that determine the life strategies of society are rooted in. These legal forms are the essence of the integrating basis of social systems, a way that ensures harmonious functioning in relationships of each other in the system. Law and its derivative, the legal aspect of life, have a deep socially interactive (communicative) nature, and social interaction itself (both in its solidary and conflict manifestations) plays an undeniable and decisive cultural and universal role in their formation and

13 See, for example: Trofimov, V.V., Sviridov, V.V. The communicative theory of society as a modern socialphilosophical approach to the study of development, ensuring the creation and reproduction of the field of law and the dynamics of the legal aspect of social life. (It is not surprising that the category of "interaction" in the framework of the social-philosophical approach developed in the works of the representatives of the "communicative theory of society" (J. Habermas, K.-O. Apel, P.A. Sorokin, T. Parsons, N. Luhmann, P. Berger, T. Luckmann, et al.) comes to the fore in terms of analyzing the laws of social development ${ }^{13}$ ).

\subsection{Conflict and solidary} nature of legal instruments. Modern social and legal life both at the microsocial level (interpersonal legal interaction, local-corporate level), at the medium social level (legal life of business corporations, public organizations, the prevailing part of municipalities), and at the macro-social level (including large social-legal communities, state formations and states, as well as the level of global scale) is, using a conventional phrase, in a permanently turbulent state. Indeed, this instability currently characterizes many

the legal aspect of social life: an introduction to the problem // Legal policy and legal life. 2017. No. 3. P.p. 16-23. 
areas of public life (economy, politics, culture, etc.); peaceful ("pacified") social environments are not many, and they are constantly affected by the negative environment. It is no accident that in modern social-philosophical literature researchers even began to use a special term characterizing this current state of society -"global risk society"(U. Beck) ${ }^{14}$. This dual unity of the negative and positive aspects of social and legal life is an objective phenomenon, but the existing predominance of the former aspect (negative manifestations) with particular acuteness raises the question of correcting this situation both at the local (regional) level and at the global level in general. This, in turn, increases the role of law, which in human civilization is perhaps the most indispensable way to solve social problems (in combination with other instruments - religious, moral, and other social regulators). The mission of law here must unconditionally rely on its "working condition", which depends on the real connection with the social context. Law should not be just a "legal

${ }^{14}$ See: Beck, U. Risk society. Towards a New Modernity / Trans. from German by V. Sedelnik and N. Fedorova. Afterword by L. Filippov. Moscow, 2000. text", but an effective system of legal instruments and mechanisms. This system can be built only by understanding the deep social laws of the legal matter.

It is important to investigate the conflicting and solidary social nature of negative and positive phenomena and processes in the legal aspect of social life, to determine the relationship between negative (conflict) and positive (cooperation) types of social interaction (social communication) and the legal regulations / norms, "matrices" of legal instruments / legal tools that are formed / acting in the context of this socio-legal dynamics, as well as types of state-legal influence (making the content of the legal regulation system), which are intended to regulate conflict and solidary relationships, organize them in a metasystem of the legal aspect of social life (such terms as "conflict law" and "cooperation law" might even be used here $\left.{ }^{15}\right)$.

These regular relationships cannot be ignored. If we analyze the norms of positive law governing the

${ }^{15}$ See: Trofimov, V.V. Conflict law and the law of cooperation // Journal of Russian Law. 2011. No. 9. P.p. 40-48. 
relations of cooperation and conflict, one cannot help but see a pattern that emphasizes the socially interactive conditionality of legal norms: systems with cooperating interests determine the quality of optionality of legal norms with potential boundaries of the "possible"; systems with competing interests determine the quality of the imperativeness of legal norms that ensure social rivalry within the framework of "permissible-due".

The corporate environment is a moral legal source that provides the individuals united and interacting on cooperation basis with established rules, as well as ways of their application. These peaceful relations between people bring about legal forms, constructions, instruments, and institutions adequate to these relations, as well as legal complexes, the elements of which can be concentrated in various legal sources. All these elements constitute the law that ensures the mutually agreed interests of the participants in the legal exchange and acquires its basic properties and qualities based on this social solidarity.

${ }^{16}$ Durkheim, E. On the division of social labor. The method of sociology. Moscow, 1991. P. 66.
Thus, the law, fixing situations of cooperation, becomes a visible symbol of social solidarity or a corporation of individuals. Where such solidarity exists, it reveals its presence by visible actions. Where it is strong, it brings people closely together, often brings them into contact, and multiplies the cases of potential relationships between the actors. The more people are solidary with each other, the more they maintain diverse relationships with each other and the number of these relations, according to E. Durkheim, "is proportional to the number of legal regulations that determine them. Indeed, social life, wherever it exists for a long time, inevitably strives to take a certain form and organize itself, and law is nothing but this organization in its most stable and precise expression... The life of society cannot develop to any point without legal life reaching the same point. Thus, we can be sure that we will find all essential varieties of social solidarity reflected in law"16.

One of its main consequences (not the only one) is the reproduction of the main forms of social solidarity in the 
form of positive (stimulating) legal instruments, which are embodied in the corresponding legal forms. Social actions (interaction of participants in legal life), reflecting positive cooperation, are most closely associated with such branches of positive law as contractual, commercial, and corporate law. Solidarity (cooperation) as a positive type of interaction, communication between individuals and social groups within the framework of micro- and macro-systems, causes the phenomenon of rapprochement of people, their contact, and, consequently, the multiplication of the cases of potential relations between them. On this basis, naturally takes placethe structuring and registration of rules of a legal nature proportional to solidary relationships. A substantial part of these rules is aimed at providing opportunities to act freely and without coercion, therefore, the process of solidarity (cooperation) of individuals is the result of the application of norms of either recommendatory or imperative nature and is regulated by positive legal

17 See: Trofimov, V.V. Positive legal instruments and the legal aspect of cooperation: formulation of the problem
693

instruments (permissions, benefits, incentives, preferences, legal stimuli) ${ }^{17}$.

The opposite of cooperation is the type of social interaction that includes the relations of struggle, rivalry, competition, or conflict, bringing about a special type of legal regulation, designed to mediate and streamline conflict relations in society. The regulations arising in the course of conflict interaction are predominantly imperative and fulfill the limiting function according to the initial social context. If we analyze the norms of positive law governing conflict relations, one cannot help but see the pattern related to the fact that in terms of their quality parameters conflict relations are, generally, the object of application of the rules of imperative legal content, introducing either direct prohibitions, for the violation of which strict sanctions are supposed, or an obligation to do something or to refrain from any action (also accompanied by sanctions for nonabiding or improper abiding with this rule), etc. And therefore, the higher the number of conflicts in social and legal life, and the more often they are, the

// Jurisprudence. 2008. No. 2. P.p. 163177. 
more restrictions there are in the law, and the more severe they are. In this sense, many of the prohibitions introduced today in legal practice have precisely this explanation - they are a reaction to real or potential conflicts between one or another side of social interaction (both in private life and in the practice of public, mainly political, discourse)).

In the event of a conflict, a deviation from the normative model of society, the state, its bodies, the status of citizens and officials takes place. To prevent a conflict situation, participants in public relations should be motivated in such a way that they do not have a desire to deviate from their "social role expectations". For this reason, if the subjects consciously do not want to act lawfully, avoiding possible conflicts with others and clashes with the normatively established order, mechanisms that are designed to encourage acting according to the rules, or to ensure conditions (forms) of coexistence in the social system that do

${ }^{18}$ See also: Trofimov, V.V. Conflict in society and the imperativeness of law: a logical relationship // Relationships in law: theory, practice, technology: a collection of articles based on materials of the International Scientific and
694

not allow potential conflicts to develop, come into force.

For participants in real or potential conflict situations, the most effective legal instrument of generating such motivation can only be a clearly established "imperative"- a barrier (boundary) that does not allow the conflict to be transferred to a state in which there will be a direct violation of the rights and interests of any of the parties conflict, or there may be prerequisites for an attempt to shatter the foundations of the social system as a whole. In other words, it can only be imperative (measures binding (including -under pain of punishment) a) to comply with the established rules in the system, or b) to act accordingly, without provoking possible conflicts, and in this sense, restrictive measures) legal requirements $^{18}$, which is mainly expressed in the form of legal prohibitions, which are "...the most

Practical Conference (Nizhny Novgorod, May 19-20, 2016) / Ed. by V.A. Tolstik, V.M. Baranov. Nizhny Novgorod: Nizhny Novgorod Academy of the Ministry of Internal Affairs, 2016. P.p. 372-376. 
pronounced, consistent, classic legal restrictions..." $"$.

The main point of imperative norms and negative (limiting) legal instruments is to fix the status of conflicting entities, determine a clear distance between them and thereby ensure proper orderliness in this system of interaction and at the same time its internal effectiveness. Criminal law, administrative offense regulations, some environmental, labor, family institutions, individual sub-institutes of civil law, institutes of procedural law, etc. can be considered as conflicting or potentially conflicting branches and institutions of law that regulate conflict relations (between criminals and victims, as well as between the person who committed an administrative offense and the one who is experiencing its negative impact, etc.).

\section{Conclusion}

Obviously, deeper and more consistent scientific research in this direction is urgently needed. A comprehensive analysis of the logical relationship of conflict and solidary types of social and legal interaction,

${ }^{19}$ Malko, A.V., Shundikov, K.V. Goals and instruments in law and legal policy. Saratov, 2003. P. 179. which constitute the content of the negative and positive sides of the legal aspect of social life, and the matter of law, represented by means of legal influence on social relations (in particular, limiting and stimulating legal tools), is extremely important today, since its heuristic results can make it possible to balance the system of social and legal life, make negativity minimally acceptable, and the positive aspect of social-legal relations absolutely necessary. The negative and positive sides of the legal aspect of social life can be understood by revealing the inherent sociallyinteractive content (conflict and solidary types of social relationships). This social context of legal life has an objective character with respect to law, determines the emergence, development, and functioning of the legal form of social relations. Having understood the nature of this conflictsolidarity social context and the reasons that give rise to negativity, and having discovered ways that enhance the positive aspect of legal life, one can find the right ways and technologies for legal 
development. The proposed approach to the subject under study significantly expands the horizons of studying legal problems, allows one to see the causes and consequences of negative and positive manifestations of the legal aspect of social life and at the same time understand what legal instruments must be developed in order to adequately and timely respond to these manifestations, providing conditions to implement the subjective rights and legitimate interests of individuals and the legal well-being of society as a whole.

Acknowledgements: The study was carried out with the financial support of the Russian Foundation for Basic Research in the framework of scientific project No. 19-011-00726

\section{References}

Joachim J. Savelsberg, Terence Halliday, Sida Liu, Calvin Morrill, Carroll Seron, Susan Silbey. Discussion Law \& Society Review at Fifty: A Debate on the Future of Publishing by the Law \& Society Association 50 (4): 1017 1036 DEC 2016 (Law and Society Review). URL: https://doi.org/10.1111/lasr.12246.

Maksymilian Del Mar. Law, Culture and Society: Legal Ideas in the Mirror of Social Theory. By Roger Cotterrell 41 (4): 983-985 DEC 2007 (Law and Society Review). URL: https://doi.org/10.1111/j.1540-

696

5893.2007.00331_1.x.

Sandra R. Levitsky, Rachel Kahn Best, Jessica Garrick. «Legality with a Vengeance»: Reclaiming Distribution for Sociolegal Studies 52 (3): 709-739 SEP 2018 (Law and Society Review).

URL: https://doi.org/10.1111/lasr.12349.

Mal'ko A.V., Trofimov V.V. Legal Life: Conceptual, Categorical and Methodological Analysis Experience // Journal of the Siberian Federal University. Series: The Humanities. 2015. Vol. 8.No. 8.P.p. 16521660.

Alekseev, S.S. Ascent to the law. Research and solutions. Moscow: "Norma" publishing house, $2001.752 \mathrm{p}$.

Aslanyan, N.P. The concept of civil law reality: formulation of the problem // Society, politics, economics, law. 2010.No.1. P.p. 69-76.

Aslanyan, N.P. The concept of legal reality: statement of a civilistic problem // Bulletin of the Irkutsk State Economic Academy. 2012.No. 5. P.p. 100-108.

Baranov, V.M. Shadowy law. Nizhny Novgorod: Nizhny Novgorod Academy of the Ministry of Internal Affairs of Russia, 2002. 165 p.

Beck, U. Risk society. Towards a New Modernity / Trans. from German by V. Sedelnik and N. Fedorova. Afterword by L. 
Filippov. Moscow: "Progress - Tradition" publishing house, 2000. $384 \mathrm{p}$.

Berger, P. \& Luckmann, T. Social structuring of reality. A treatise on the sociology of knowledge. Moscow: “Medium" publishing house, 1995. 323 p.

Bryzgalov, A.I. On some theoretical and methodological problems of legal science at the present stage // State and Law. 2004.No. 4. P.p. 17-22.

Bryzgalov, A.I. Jurisprudence today: theoretical and methodological problems that await solutions // Journal of Russian Law. 2001.No. 6. P.p. 44-50.

Grevtsov, Yu.I. Sociology: Lecture course. St. Petersburg: "Press" legal center, 2003. 467 p.

Durkheim, E. On the division of social labor. The method of sociology. Moscow: Nauka Publishers, 1991. 575 p.

Zatonsky, V.A., Mal'ko, A.V. The category of "legal life": the experience of theoretical understanding // Jurisprudence. 2006. No.4. P.p. 4-17.

Lichman, B.V. The multi-conceptual methodology of Russian jurisprudence // Bulletin of the Ural Institute of Economics, Management and Law. 2013.No. 2. P.p. 60-67.

Malakhov, V.P., Eriashvili, N.D. Legal aspect of life, its content and forms // Methodological and worldview problems of
697

modern legal theory.Moscow: "UNITY DANA” publishers, 2011. 431 p. P.p. 74-90. Mal'ko, A.V. The category of "legal life": problems of formation // State and Law. 2001. No. 5. P.p. 5-13.

Mal'ko, A.V., Mikhailov, A.E. The legal aspect of social life: textbook. Saratov: Publishing House of the Saratov State Academy of Law, 2007. 164 p.

Mal'ko, A.V., Ponomarenkov, V.A. Legal life of modern society: social factor analysis: monograph. Moscow: "Yurlitinform" publishers, 2015. $152 \mathrm{p}$.

Mal'ko, A.V., Trofimov, V.V. The legal life of society as an object of legal policy in the context of globalization and regionalization: monograph. Moscow: "Justice" publishing house, 2018. 236 p.

Mal'ko, A.V., Trofimov, V.V. The legal life of society as an object of the theory of law (to the formulation of the problem) // State and Law.2017.No. 5. P.p. 39-50.

Mal'ko, A.V., Trofimov, V.V. Theoretical and methodological significance of the concept of "legal life" // State and Law.2010. No. 7. P.p. 5-13.

Malko, A.V., Shundikov, K.V. Goals and instruments in law and legal policy. Saratov: Publishing house of the Saratov State Academy of Law, 2003. 296 p.

Matuzov, N.I. Legal life as an object of scientific research // Legal life in modern Russia: theoretical and methodological aspect / Ed. by N.I. Matuzov \& A.V. 
698

Mal'ko. Saratov: Publishing house of the

Saratov State Academy of Law, 2005. P.p. 9-38.

Nevvazhay, I.D. History and philosophy of science. In 2 parts. Part 2: Philosophical problems of social and humanitarian (legal) sciences. Saratov: Publishing house of the Saratov State Academy of Law, 2012. 276 p.

Nozdrin, A.N. Legal life as a category of modern legal science: Author's abstract of dissertation for the degree of Cand. Sc. (Law).Mariupol, 2013. 24 p.

Polyakov, A.V. Communicative legal understanding: Selected works. St. Petersburg: "Alef-Press" publishing house, 2014. 575 p.

Law and culture: Monograph / Ed. by N.S. Sokolova. Moscow: Publishing House of the Peoples' Friendship University of Russia, 2002. 423 p.

Legal life in modern Russia: theoretical and methodological aspect / Ed. by N.I. Matuzov \& A.V. Mal'ko.Saratov: Publishing house of the Saratov State Academy of Law, 2005. $528 \mathrm{p}$.

The legal life of society: problems of theory and practice / Ed. by A.V. Mal'ko. Moscow: Prospekt publishing house, 2016. 488 p.

The legal life of Russian society in the context of globalization / Ed. by A.V. Mal'ko.Moscow: Prospekt publishing house, 2017. $320 \mathrm{p}$.
Legal life of modern Russian society: levels, sections, segments: monograph / Ed. by D. Sc. (Law), prof. A.V. Malko.Moscow: "Yurlitinform" publishers, 2016. 360 p.

Sorokin, P.A. Public textbook of sociology. Articles of different years. Moscow: Nauka Publishers, 1994. $560 \mathrm{p}$.

Trofimov V.V. Conflict in society and the imperativeness of law: a logical relationship // Relationships in law: theory, practice, technology: a collection of articles based on materials of the International Scientific and Practical Conference (Nizhny Novgorod, May 19-20, 2016) / Ed. by V.A. Tolstik, V.M. Baranov. Nizhny Novgorod: Nizhny Novgorod Academy of the Ministry of Internal Affairs, 2016. P.p. 372-376.

Trofimov, V.V. Conflict law and the law of cooperation // Journal of Russian Law. 2011.No. 9. P.p. 40-48.

Trofimov, V.V. The concept of legal life: theoretical and methodological significance // Legal policy and legal life.2009. No. 2. P.p. 61-68.

Trofimov, V.V. Positive legal instruments and the legal aspect of cooperation: formulation of the problem // Jurisprudence. 2008.No. 2. P.p. 163177. 
Trofimov, V.V. Legal life: theoretical and socio-philosophical problems of research // Legal policy and legal life.2003.No. 4.P.p. 124-133.

Trofimov, V.V. Socially-interactive (communicative) environment and its cultural-universal role in the processes of legal dynamics // Legal Technology.2016.No. 10.P.p. 316-321.

Trofimov, V.V. The socially interactive nature of the legal aspect of life as a dynamic process // Legal policy and the legal aspect of life. 2016.No. 3.P.p. 13-21.

Trofimov, V.V., Sviridov, V.V. The communicative theory of society as a modern social-philosophical approach to the study of the legal aspect of social life: an introduction to the problem // Legal policy and legal life. 2017.No. 3. P.p. 1623.

Chernykh, E.N. The category of "legal life": issues of methodology // Legal policy and legal life. 2014.No. 3. P.p. 815.

Shiyanov, V.A. The legal system and the legal aspect of social life: theoretical aspect of interaction: Author's abstract of dissertation for the degree of Cand. Sc. (Law). Moscow: Moscow new legal Institute, 2008. 26 p.

Shundikov, K.V. Synergetic approach in jurisprudence. Problems of methodology and experience of theoretical application:
699

monograph. Moscow: "Yurlitinform" publishers, 2013. $256 \mathrm{p}$ 